Research Article

\title{
To study the efficacy and tolerability of fenugreek seed powder as add- on therapy with metformin in patients of type- 2 diabetes mellitus
}

\author{
Manmeet Kaur $^{1 *}$, Narinder Singh ${ }^{1}$, Geeta Sharma ${ }^{1}$, Davinder Singh ${ }^{2}$
}

\begin{abstract}
${ }^{1}$ Department of Pharmacology, Sri Guru Ram Das Institute of Medical sciences and Research, Amritsar, India,

${ }^{2}$ Department of Medicine, Sri Guru Ram Das Institute of Medical sciences and Research, Amritsar, India
\end{abstract}

Received: 23 December 2015 Accepted: 03 February 2016

\section{*Correspondence to:}

Dr. Manmeet Kaur,

Email: drmanmeet26@ hotmail.com

Copyright: (C) the author(s), publisher and licensee Medip Academy. This is an openaccess article distributed under the terms of the Creative Commons Attribution NonCommercial License, which permits unrestricted noncommercial use, distribution, and reproduction in any medium, provided the original work is properly cited.

\begin{abstract}
Background: Fenugreek, an ancient herb has been known for its culinary and medicinal value in Indian Subcontinent. Its seeds, rich in fibers and phytochemical compounds, have been investigated for their hypoglycemic and multiple benefits. This study was thus undertaken to assess the antihyperglycemic effect of fenugreek seeds in patients of Type 2 Diabetes Mellitus (DM) as add-on therapy with metformin.

Methods: An open-labelled comparative study of 12 weeks duration was conducted on patients (randomly divided in 2 groups of 30 each) of Type 2 DM. Group 1 was given metformin $500 \mathrm{mg}$ twice a day while group 2 was given 500 $\mathrm{mg}$ of metformin along with fenugreek seed powder capsule, $1 \mathrm{gm}$ thrice a day. Weekly evaluation for fasting and post-prandial blood sugar was done. HbAlc estimation was done at the beginning and at the end of the study. Student's t-test (paired and unpaired) was applied for statistical analysis.

Results: After 12 weeks of treatment, there was significant fall in fasting, as well as postprandial blood sugar and HbAlc levels in group 1 and group 2. However this improvement was statistically more significant in group 2 when compared to group 1 .

Conclusions: This study shows the beneficial effects of fenugreek seeds on glycemic profile in patients of Type $2 \mathrm{DM}$ and can be used as an add-on therapy with metformin in management of Type 2 DM.
\end{abstract}

Keywords: Type 2 Diabetes Mellitus (DM), Fenugreek

\section{INTRODUCTION}

Diabetes Mellitus (DM) refers to group of common metabolic disorders that share the common phenotype of hyperglycaemia. The different types of DM are caused by the complex interplay of genetic and environmental factors. The factors that lead to hyperglycaemia are decrease insulin secretion, reduced glucose utilization and increased glucose production. ${ }^{1}$ Symptoms of hyperglycaemia include polyuria, polydipsia, weight loss, sometimes weight loss with polyphagia and blurred vision.
The risk of developing Diabetes Mellitus increases with increasing age, lack of physical activity, obesity, individuals with hypertension, dyslipidemia, women with prior gestational Diabetes Mellitus and with certain racial and ethnic groups having a strong genetic predisposition. Diabetes Mellitus is classified on the basis of the pathogenic process that leads to hyperglycaemia .The two broad categories of DM are Type 1 and Type 2. Both of these types of diabetes are preceded by a phase of abnormal glucose homeostasis as the pathogenic process. The other categories that have been evolved are on the basis of aetiology. e. g. gestational diabetes, drug induced diabetes and hyperglycaemia associated with a myriad number of reasons. ${ }^{2}$ 
Type-1 Diabetes Mellitus (immune mediated diabetes or insulin-dependent diabetes or juvenile onset diabetes) is the result of a cell- mediated auto-immune destruction of $\beta$-cells in the pancreas. Type-2 Diabetes Mellitus (Noninsulin-dependent Diabetes or Adult-onset Diabetes) constitutes about $90-95 \%$ of all the reported cases of Diabetes. It encompasses individuals who have insulin resistance and relative (rather than absolute) insulin deficiency. ${ }^{3}$ There could be a predominantly insulin secretory defect with insulin. Type-2 Diabetes Mellitus is at present one of the most challenging health care problems, which require optimum management. The treatment of Type-2 Diabetes Mellitus aims at providing structured education to the patients with Type-2 Diabetes Mellitus and to improve the overall quality of life by providing psychological and pharmacological support. ${ }^{4}$

An HbA1c target of $7 \%$ among the people with Type-2 Diabetes mellitus is reasonable to reduce the risk of micro-vascular and macro-vascular complications. ${ }^{5}$ The treatment of the patients with type $2 \mathrm{DM}$ should include diet, life style modifications (exercise, smoking cessation), good glycemic control with medical nutrition therapy. ${ }^{1}$

Many conventional drugs have been derived from prototypic molecules in medicinal plants. Metformin exemplifies an efficacious oral glucose lowering agent. Its development was based on the use of Galega officinalis to treat Type 2 DM. $^{6}$

Presently metformin has been incorporated in the early stage of management of Type 2 DM as the first choice oral agent, along with appropriate diet control and lifestyle advice. ${ }^{7}$ Alternate therapies with anti-diabetic activity have also been researched relatively extensively in India. The World Health Organization Expert Committee on diabetes has recommended that traditional medicinal herbs be further investigated for the treatment of Diabetes. ${ }^{6}$

Fenugreek (Trigonella foenum graceum ) is one of the oldest herb used for medicinal purposes in India and its history dates back to Egyptian civilization. ${ }^{8}$ Fenugreek seeds contain alkaloids, including trigonelline, gentianine and carpaine compounds. These seeds are a rich source of fiber and protein. The fiber may be further classed as gum (gel fiber) and neutral detergent fiber. ${ }^{1,6,8}$ The seeds also contain fibre-galcatomannan, 4-hydroxyisoleucine- a novel amino acid and fenugreekine, a component that may have hypoglycemic activity. ${ }^{9}$ Lignin, another form of crude fiber, is not a carbohydrate per se, but it is of plant origin and is also indigestible, which prevents the rapid uptake of glucose in the small intestine, slows gastric emptying, aids in blood sugar retention in diabetic patients and may also be effective in the treatment of hypercholesterolemia. ${ }^{10}$

Broca et al reported that the hypoglycemic action of fenugreek seeds is exerted through 4- hydroxyleucine which stimulates insulin secretion. Thus acting as a secretagogue. ${ }^{11}$

Thus the present study was designed to study the efficacy of fenugreek seed powder used as add-on therapy with metformin in patients of Type-2 Diabetes mellitus and to compare the variations in blood glucose levels with fenugreek seed powder and metformin combination versus metformin alone in patients of Type-2 Diabetes mellitus. And additionally to study the safety and tolerability of fenugreek seed powder along with metformin in patients of Type-2 Diabetes mellitus.

\section{METHODS}

This twelve week long, open, standard controlled and parallel randomized study involved 60 patients, of either sex, with Type $2 \mathrm{DM}$, fulfilling the inclusion criteria and attending the Medicine OPD at Sri Guru Ram Das Charitable Hospital attached to Sri Guru Ram Das Institute of Medical Sciences and Research, Vallah, Amritsar. The patients were randomly distributed into two groups, i.e. Group 1 and Group 2 consisting of thirty patients each. Written Informed Consent was taken from the patients to be included in the present study and all the risks and the benefits were explained to each patient in their own language. Patients were advised to undertake diet control and regular exercise as per the protocol designed by W.H.O.

\section{Inclusion criteria}

Newly diagnosed Type-2 Diabetes Mellitus (Type 2 DM) patients of either sex, aged 30-70 years, having Fasting Blood Glucose $>126 \mathrm{mg} / \mathrm{dl}$ were included in the study.

\section{Exclusion criteria}

1. Patients with Type-1 Diabetes Mellitus.

2. Patients with history of ketoacidosis in the past.

3. Patient with a history of hypersensitivity to fenugreek seed powder.

4. Patient with a history of bleeding disorders.

5. Patient with a history of surgery in the past six weeks.

6. Pregnant females.

7. Patient with a history of drug abuse and steroid treatment.

\section{Intervention}

Patients in Group 1 were given only Metformin $500 \mathrm{mg}$ twice a day after meals for 12 weeks. Patients in Group 2 were given fenugreek seed powder capsules in a dose of 1 capsule of $1 \mathrm{gm}$ each thrice a day before meals along with Metformin $500 \mathrm{mg}$ twice a day after meals for 12 weeks.

The patients were investigated for FBG and PPBG every week for twelve weeks. While HbA1c estimation was 
done at the beginning of the study and at the end of the study.

The patients were advised to report immediately in case they developed any adverse reaction e.g. nausea, vomiting, abdominal pain, muscle ache, fever, weight gain, diarrhoea, flatulence or any other type of side effect.

\section{Statistical Analysis}

Statistical analysis was done using Student's paired and unpaired ' $t$ ' test. Paired ' $t$ ' test was done to determine the significance within the groups and unpaired ' $t$ ' test was done to determine the significance between the groups. The results of the study are depicted in the tables and the graphs. The level of significance was determined as its 'p' value with $\mathrm{p}>0.05$ taken as not significant, $\mathrm{p}<0.05$ taken as significant at $5 \%$ significance level, $\mathrm{p}<0.01$ taken as significant at $1 \%$ significance level \& p $<0.001$ taken as highly significant.

\section{RESULTS}

In this study 60 (36 males and 24 females) patients were randomly distributed in 2 groups by a computer generated series. The mean age of the patients at the time of visit in Group 1 is $53.23 \pm 8.19$ years and in Group 2 was $52.97 \pm 8.00$ years which was statistically not significant. There was not much difference in the baseline Body Mass Index (BMI) of both the groups with the patients in the Group 1 having a BMI of $25.91 \pm 1.92$ and the patients in Group 2 having a BMI $25.17 \pm 2.88$ indicating that majority of the patients were overweight. There was not much fluctuation in the BMI at the end of study (Table $1)$.

Table 1: Anthropometric comparison of group 1 and group 2.

\begin{tabular}{|lllllll|}
\hline & Group 1 $(\mathbf{n}=\mathbf{3 0})$ & & Group 2 $(\mathbf{n = 3 0})$ & & \\
\hline & Day 0 & $12^{\mathrm{TH}}$ Week & P value & Day 0 & $12^{\mathrm{TH}}$ Week & P value \\
\hline Weight $(\mathrm{kg})$ & $70.4 \pm 11.53$ & $69.33 \pm 11.42$ & $\mathrm{~ns}$ & $69.9 \pm 12.77$ & $68.05 \pm 12.51$ & $\mathrm{~ns}$ \\
\hline Height $(\mathrm{cm})$ & $164.23 \pm 8.36$ & ----- & $\mathrm{ns}$ & $166 \pm 8.67$ & ----- & $\mathrm{ns}$ \\
\hline BMI $\left(\mathrm{kg} / \mathrm{m}^{2}\right)$ & $25.91 \pm 1.92$ & $25.51 \pm 1.91$ & $\mathrm{~ns}$ & $25.17 \pm 2.88$ & $24.49 \pm 2.74$ & $\mathrm{~ns}$ \\
\hline
\end{tabular}

Table 2 : Fasting blood glucose levels (Mean \pm SD) on day zero, 1st, 2nd, 3rd, 4th, 5th, 6th,7th, 8th, 9th, 10th, 11th, 12th week in group 1 and group 2.

\begin{tabular}{|lllll|}
\hline Duration & Group 1(n=30) & & Group 2 $(\mathbf{n = 3 0})$ & Change from baseline \\
\hline & Mean \pm SD & Change from baseline & Mean \pm SD & ------ \\
\hline Day 0 & $162.0667 \pm 11.17$ & -------- & $164.1333 \pm 17.79$ & $1.86 \pm 11.78^{\mathrm{NS}}$ \\
\hline $1^{\text {st }}$ week & $158.56 \pm 11.11$ & $3.5 \pm 1.52^{\mathrm{HS}}$ & $162.267 \pm 24.26$ & $8.96667 \pm 9.90^{\mathrm{HS}}$ \\
\hline $2^{\text {nd }}$ week & $156 . .53 \pm 10.77$ & $5.53 \pm 2.14^{\mathrm{HS}}$ & $155.166 \pm 15.91$ & $11.66667 \pm 8.99^{\mathrm{HS}}$ \\
\hline $3^{\text {rd }}$ week & $154.56 \pm 10.64$ & $7.50 \pm 1.96^{\mathrm{HS}}$ & $152.46 \pm 14.48$ & $12.30 \pm 10.67^{\mathrm{HS}}$ \\
\hline $4^{\text {th }}$ week & $152.20 \pm 10.68$ & $9.86 \pm 2.73^{\mathrm{HS}}$ & $151.83 \pm 16.06$ & $15.333 \pm 9.7^{\mathrm{HS}}$ \\
\hline $5^{\text {th }}$ week & $150.60 \pm 10.23$ & $11.46 \pm 2.96^{\mathrm{HS}}$ & $148.80 \pm 16.81$ & $18.866 \pm 10.20^{\mathrm{HS}}$ \\
\hline $6^{\text {th }}$ week & $148.60 \pm 10.20$ & $13.46 \pm 2.64^{\mathrm{HS}}$ & $145.26 \pm 16.44$ & $20.033 \pm 11.77^{\mathrm{HS}}$ \\
\hline $7^{\text {th }}$ week & $146.4333 \pm 10.04$ & $15.63 \pm 2.73^{\mathrm{HS}}$ & $144.10 \pm 12.89$ & $22.900 \pm 13.22^{\mathrm{HS}}$ \\
\hline $8^{\text {th }}$ week & $144.43 \pm 9.86$ & $17.63 \pm 3.20^{\mathrm{HS}}$ & $141.23 \pm 10.11$ & $26.766 \pm 11.37^{\mathrm{HS}}$ \\
\hline $9^{\text {th }}$ week & $142.40 \pm 9.8$ & $19.66 \pm 3.07^{\mathrm{HS}}$ & $137.36 \pm 11.00$ & $30.30 \pm 14.02^{\mathrm{HS}}$ \\
\hline $10^{\text {th }}$ week & $140.30 \pm 9.8$ & $21.76 \pm 3.71^{\mathrm{HS}}$ & $133.83 \pm 9.3$ & $33.83 \pm 14.02^{\mathrm{HS}}$ \\
\hline $11^{\text {th }}$ week & $138.26 \pm 9.8$ & $23.80 \pm 3.77^{\mathrm{HS}}$ & $130.30 \pm 10.12$ & $37.30 \pm 14.74^{\mathrm{HS}}$ \\
\hline $12^{\text {th }}$ week & $136.23 \pm 9.18$ & $25.83 \pm 4.18^{\mathrm{HS}}$ & 126.8333 & \\
\hline
\end{tabular}

Fasting Blood Glucose FBG) levels were measured at the beginning of the study and then weekly till the end of 12 weeks. There was a significant reduction in mean FBG levels of both the groups. However, the reduction in mean FBG level in Group 2 was greater than in Group 1 $(p<0.001)$. An analysis of the mean percentage in FBG levels of both group at the end of 12 weeks revealed greater reduction in group $1 .(\mathrm{p}<0.001)$ (Figure 1 , Table 2).
Mean Baseline Post Prandial Blood Glucose (PPBG) levels was greater in Group $1(222.73 \pm 12.44 \mathrm{mg} / \mathrm{dl})$ as compared to Group $2(213.56 \pm 23.21 \mathrm{mg} / \mathrm{dl})$. However there was a greater reduction in PPBG levels in Group 2 as compared to Group 1. Furthermore mean percentage change was greater in Group 2 than in Group $1(\mathrm{p}<0.001)$ (Figure 2, Table 3). 


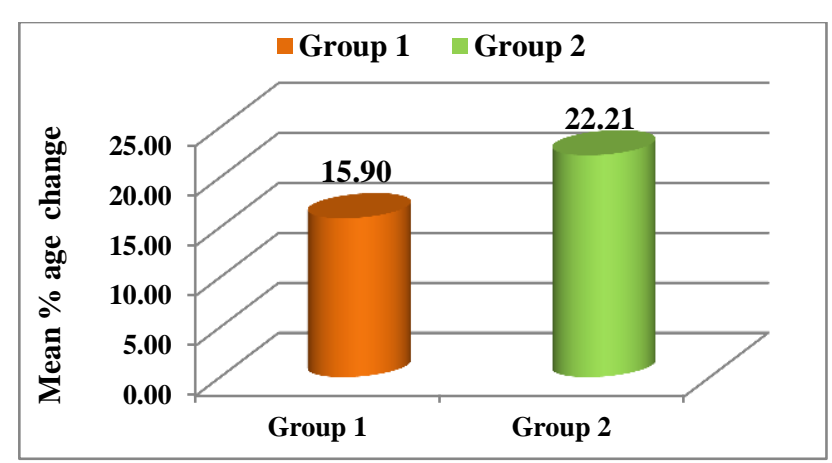

Figure 1: Mean percentage change in fasting blood glucose in group 1 and group $2(p<0.001$ in both the groups).

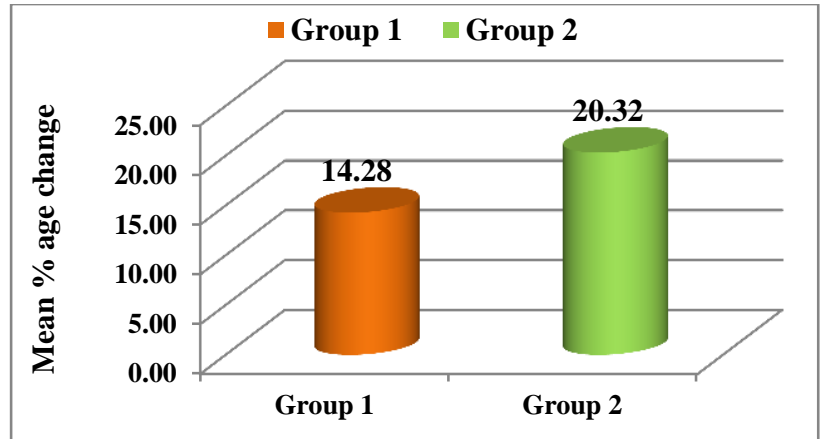

Figure 2: Mean percentage change in post prandial blood glucose in group 1 and $2(p<0.001$ in both the groups).

Table 3: Post prandial blood glucose levels (Mean \pm SD) on day zero, $1^{\text {st }}, 2^{\text {nd }}, 3^{\text {rd }}, 4^{\text {th }}, 5^{\text {th }}, 6^{\text {th }}, 7^{\text {th }}, 8^{\text {th }}, 9^{\text {th }}, 10^{\text {th }}, 11^{\text {th }}, 12^{\text {th }}$ week in group 1 and group.

\begin{tabular}{|lllll|}
\hline Duration & Group1 $(\mathbf{n}=\mathbf{3 0})$ & & Group2 $(\mathbf{n}=30)$ & Change from baseline \\
\hline & Mean \pm SD & Change from baseline & Mean \pm SD & $\ldots \ldots$. \\
\hline Day 0 & $222.73 \pm 12.44$ & $\ldots \ldots \ldots$ & $213.56 \pm 23.21$ & $6.44 \pm 4.10^{\mathrm{HS}}$ \\
\hline $1^{\text {st }}$ week & $219.86 \pm 11.7$ & $2.86 \pm 2.02^{\mathrm{HS}}$ & $207.1 \pm 21.85$ & $8.9 \pm 14.82^{\mathrm{S}}$ \\
\hline $2^{\text {nd }}$ week & $217.33 \pm 11.77$ & $5.4 \pm 2.11^{\mathrm{HS}}$ & $204.66 \pm 17.84$ & $15.3 \pm 11.38^{\mathrm{HS}}$ \\
\hline $3^{\text {rd }}$ week & $214.33 \pm 12.06$ & $8.4 \pm 2.017^{\mathrm{HS}}$ & $198.20 \pm 16.63$ & $18.86 \pm 12.67^{\mathrm{HS}}$ \\
\hline $4^{\text {th }}$ week & $211.50 \pm 11.96$ & $11.23 \pm 2.96^{\mathrm{HS}}$ & $194.7 \pm 15.4$ & $21.40 \pm 16.12^{\mathrm{HS}}$ \\
\hline $5^{\text {th }}$ week & $209.33 \pm 12.12$ & $13.4 \pm 3.00^{\mathrm{HS}}$ & $192.16 \pm 15.83$ & $30.16 \pm 18.4^{\mathrm{HS}}$ \\
\hline $6^{\text {th }}$ week & $205.73 \pm 11.91$ & $17.00 \pm 2.80^{\mathrm{HS}}$ & $185.96 \pm 19.7$ & $30.46 \pm 18.9^{\mathrm{HS}}$ \\
\hline $7^{\text {th }}$ week & $203.56 \pm 11.7$ & $19.16 \pm 2.9^{\mathrm{HS}}$ & 183.4017 .9 & $34.96 \pm 17.8^{\mathrm{HS}}$ \\
\hline $8^{\text {th }}$ week & $200.266 \pm 11.7$ & $22.46 \pm 2.75^{\mathrm{HS}}$ & $183.1 \pm 12.26$ & $37.26 \pm 18.89^{\mathrm{HS}}$ \\
\hline $9^{\text {th }}$ week & $198.36 \pm 12.52$ & $24.36 \pm 3.17^{\mathrm{HS}}$ & $178.60 \pm 12.20$ & $37.26 \pm 18.89^{\mathrm{HS}}$ \\
\hline $10^{\text {th }}$ week & $195.32 \pm 11.96$ & $27.40 \pm 3.31^{\mathrm{HS}}$ & $176.30 \pm 12.04$ & $39.93 \pm 19.10^{\mathrm{HS}}$ \\
\hline $11^{\text {th }}$ week & $193.00 \pm 11.96$ & $29.73 \pm 3.0^{\mathrm{HS}}$ & $173.63 \pm 10.53$ & $44.53 \pm 18.7^{\mathrm{HS}}$ \\
\hline $12^{\text {th }}$ week & $191.00 \pm 12.69$ & $31.73 \pm 2.76^{\mathrm{HS}}$ & $169.03 \pm 12.62$ & 4.3 \\
\hline
\end{tabular}

Group 2 showed a greater reduction in HbA1c levels as compared to Group 1 at the end of 12 weeks of study. However there was a highly significant reduction in HbA1c levels in both the groups $(\mathrm{p}<0.001)$ (Figure 3).

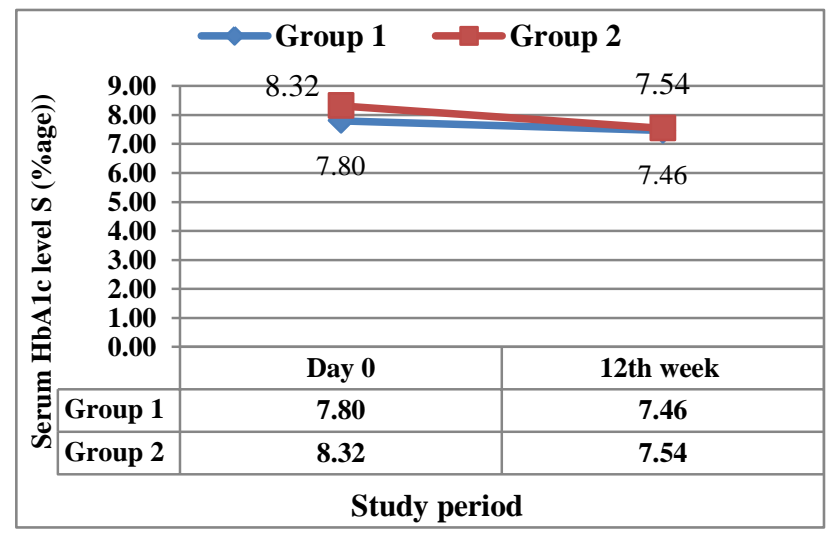

Figure 3: Serum hba1c levels on day 0 and 12th week in group 1 and group 2.
Table 4: Incidence of adverse effects in group 1 and group 2.

\begin{tabular}{|lll|}
\hline Adverse effect & $\begin{array}{l}\text { Group 1 N } \\
(\%)\end{array}$ & $\begin{array}{l}\text { Group 2 N } \\
(\%)\end{array}$ \\
\hline Wheezing $\backslash$ Rhinnorhea & 0 & 0 \\
\hline diarrhoea & 0 & $1(3 \%)$ \\
\hline Flatulence & 0 & $1(3 \%)$ \\
\hline Nausea $\backslash$ Vomiting & 0 & $1(3 \%)$ \\
\hline Facial swelling & 0 & $1(3 \%)$ \\
\hline Bleeding tendency & 0 & 0 \\
\hline Fainting & 0 & 0 \\
\hline Numbness & 0 & 0 \\
\hline Hypoglycemia & 0 & 0 \\
\hline Pallor & 0 & 0 \\
\hline Tiredness/ Weakness & 0 & 0 \\
\hline Any other (itching) & 0 & $1(3 \%)$ \\
\hline
\end{tabular}

No side effects were reported in Group 1. While in Group 2 diarrhoea, nausea/ vomiting, facial swelling, flatulence and itching each was reported in $3 \%$ of the patients. All 
the adverse effects were mild in nature and none of the patients was withdrawn from the study (Table 4).

\section{DISCUSSION}

Type $2 \mathrm{DM}$ is a group of metabolic disorders characterized by hyperglycemia resulting from defects in insulin secretion, insulin action or both. ${ }^{1}$ Type 2 DM usually precipitates from the inability of the pancreatic beta cells to adapt to the reductions in insulin sensitivity that occur over a life time. The most common factors that place an increased burden on beta cells are puberty, overeating, sedentary life style, pregnancy leading to weight gain and hypertension. An underlying genetic predisposition also appears to be critical. ${ }^{12,13}$

The present study was conducted in this institute from September 2013- Sept 2015. In this study we compared the anti-hyperglycemic effect of fenugreek as an adjunct to metformin and metformin when used alone in the treatment of Type 2 DM patients. Sixty patients of Type $2 \mathrm{DM}$ were included in the study and were divided in two groups of 30 each. Group 1 received metformin $500 \mathrm{mg}$ twice daily after meals. Group 2 received metformin 500 mg twice daily after meals along with fenugreek seed powder in a dose of 1 capsule thrice a day (1 capsule containing $1 \mathrm{gm}$ ). The patients in each group received the treatment for 12 weeks duration.

There was a significant decline $(\mathrm{p}<0.05)$ in the mean FBG in Group 1 patients. Similarly there was a highly significant reduction $(\mathrm{p}<0.001)$ in $\mathrm{FBG}$ in Group 2 patients. However the reduction in Group 2 was greater than in Group 1. Similarly there was a highly significant $(\mathrm{p}<0.001)$ reduction in PPBG in both the groups. This is supported by studies conducted by Bordia et al. ${ }^{14}$ However the reduction in PPBG was greater in Group 2. Besides this, there was a highly significant reduction in HbA1c levels in both the groups $(p<0.001)$. However the mean decrease in $\mathrm{HbA1c}$ was greater in Group 2 as compared to Group 1. The results of the present study are supported by a randomized control trial conducted by Ansari, et al in which fenugreek seed powder was administered as an add- on therapy to Type 2 DM patients for a duration of three months resulted in significant reduction in HbA1c levels $(\mathrm{p}<0.001)$.

Similar findings were present in the study conducted by Lu et al where fenugreek seed powder was used as addon therapy along with anti-hyperglycaemic agents in Type 2 DM patients for 12 weeks duration. At the end of 12 weeks the treated group in which fenugreek seed powder was used as an add-on therapy to the antihyperglycaemic agent showed statistically decrease in FBG, 2h PPBG, HbA1c as compared to those in the control group who received only anti-hyperglycaemic agent $(\mathrm{p}<0.05){ }^{15}$

A landmark study was conducted by Gupta et al in 2001 to evaluate the effect of fenugreek seed on the glycemic control and insulin resistance in Type 2 DM patients for a period of two months. For that study 1 gm/day hydroalcoholic extract of fenugreek was taken. There was a significant improvement in the FBG and PPBG.. These findings are very much supportive to those in the present study where there was significant improvement in glycemic profile of the patient. ${ }^{16}$

The mechanism of hypoglycemic effect of fenugreek seeds in Diabetes is usually associated with the insulin signalling pathway. The fenugreek seed activate the insulin receptors and its downstream signalling molecules in adipocytes and liver cells. In an experiment conducted by Vijayakumara et al alloxan was given intraperitoneally to albino mice. ${ }^{17}$ The active principle responsible for antihyperglycemic activity is largely due to fenugreeks saponins, high fibre content, the amino acid hydroxyisoleucine and the major alkaloid trigonelline. Anti-hyperglycemic effect was due to stimulation of insulin secretion and delayed gastric emptying caused by high fibre content, inhibiting carbohydrate enzymes. This is further supported by various studies by Ramesh Babu et al, Muraki et al, Puri, et al. ${ }^{18-20}$ Hydroxyleucine fraction is also responsible for anti-hyperglycemic action by non-insulin dependent pathway as demonstrated by Haeri, et al and is a potent secretor of insulin secretion as stated by Sauvaire, et al. ${ }^{21,22}$ The active subfraction is contained in the testa and endosperm of fenugreek as was confirmed by the animal studies conducted by Ribes, et al. $^{23}$

As far as our study was concerned no major side effects were reported in Group 1. While in Group 2 one case each of nausea/vomiting, diarrhoea, facial swelling, bleeding tendency and itching were reported, which were mild in nature.

Neelakantan, et al conducted a meta- analysis and reported the adverse effects that occurred with the use of fenugreek seed powder in Type 2 DM patients. In one study conducted by Chevassus one mild case of abdominal symptoms was reported. ${ }^{11}$ As already mentioned the study conducted by Gupta et al on 12 patients, 5 patients developed dyspepsia and mild abdominal symptoms. ${ }^{16} \mathrm{Lu}$ et al reported that of the 46 patients in the treatment group, two developed abdominal discomfort and nausea and one patient developed diarrhoea. The symptoms disappeared once the drug was withdrawn for 2 days. Again after resuming the treatment, no adverse reaction appeared and all patients completed the trial. ${ }^{15}$

\section{CONCLUSION}

The present study demonstrated that fenugreek seed powder when used as add-on therapy with metformin in Type 2 DM has a significant effect on glycemic profile. Thus we conclude that fenugreek seed powder may be a promising additional therapy for the management of Type $2 \mathrm{DM}$ as these are widely available at low cost in third world countries like India.

Funding: No funding sources Conflict of interest: None declared

Ethical approval: The study was approved by the Institutional Ethics Committee 


\section{REFERENCES}

1. Powers AC. Diabetes Mellitus. In: Fauci AS, Braunwald E, Kasper DL, Stephen LH, Dan LL, Jameson JL, LoscalzoJ, editors .Harrison's Principles of Internal Medicine. $18^{\text {th }} \mathrm{ed}$. New York: McGraw Hill. 2012:2968-3002.

2. American Diabetes Association. Diagnosis and Classification of Diabetes Mellitus. Diabetes Care. 2012;35(1):65-71.

3. American Diabetes Association. Standards of Medical Care in Diabetes. Diabetes Care. 2013;36(1):1-114.

4. Martha M, Kennedy N. Pancreatic hormone and anti-diabetic drugs. In: Katzung BG, Masters SB, Trevor AI, editors. Basic and Clinical Pharmacology. 12thed. New Delhi: Tata McGraw Hill. 2012:753-67.

5. Management of Diabetes. A national clinical guideline. Edinburgh; Scottish Intercollegiate Guideline Network: 2010:10-50. Available from:www.sign.ac.uk/guidelines/fulltext/50/index. html.

6. Olefsky JM. Insulin resistance and pathogenesis of non-insulin dependent diabetes mellitus: cellular and molecular mechanisms. In: Efendic S, Ostens on CG, Vranic M, editors. New concept in the Pathogenesis of NIDDM. New York: Plenum Publishing Corporation. 1999.

7. Davidson MB, Diabetes Mellitus: Diagnosis and Treatment. 21 New York, NY. Churchill Livingstone. 2010:795-835.

8. Ansari R, Ansari S. Effectiveness of fenugreek for lowering the hemoglobin $(\mathrm{HbA} 1 \mathrm{c})$ in the patients with self-management of type 2 diabetes: A Randomized Control Trial. Medical Complication of Type-2 Diabetes. Dr. Collen Croniger (Ed). 2011. SBN; 978-953-307-367.InTech.Available from:http: //www.intechopen. com/books/medicalcomplications-of-type-2-diabetes/effectiveness-offenugreek-for-loweriong-haemoglobin-hbalcinpatients-with-self-management-of-type-2-diabeteS

9. Morcos SR, Elhawary Z, Gabrial GN. Protein rich food mixtures for feeding the young in Egypt. $\mathrm{Z}$ Ernahrungswiss. 1981;20:275-82.

10. Kumar VS, Rama Rao DKA, Mohanty S. Comparative study of fenugreek seeds on glycemic index in high and medium dietary fibre containing diets in NIDDM Patients. NJIRM. 2011;2(3):29-37.

11. Neelkantan N, Naranyanan M, J de Souza R, van Dam RM. Effect of fenugreek (Trigonella foenumgraceum L.) intake of glycemia:a meta-analysis of clinical trials . Nutritional J. 2014;13;1-11.

12. Buse JB, Polonsky KS, Burant CF. Type 2 Diabetes Mellitus. In: Melmed S, Polonsky KSN, Larsen PR, Kronenber HM, editors. Williams Book on
Endocrinology. 12TH ed. New Delhi. Elsevier Saunders: 2012:1371-1434.

13. Valliyot B, Sreedharan J, Muttappallymyalil J, Valliyot SB. Risk factors of type 2 diabetes mellitus in the rural population of north kerala, india: a case control study. Diabetologia Croatica. 2013;42(1):3340.

14. Bordia A, Verma SK, Srivastava KC. Effect of ginger (Zingiber officinale Rosc.) and fenugreek (Trigonella foenumgraecum L.) on blood lipids, blood sugar and platelet aggregation in patients with coronary artery disease. Prostaglandins Leukot Essent Fatty Acids. 1997;56(5):379-84.

15. Lu FR, Shen L, Qin Y, Gao L, Li H, Dai Y. Clinical observation on trigonella foenum-graecum L. total saponins in combination with sulfonylureas in the treatment of type 2 diabetes mellitus. Chin J Integr Med. 2008;14(1):56-60.

16. Gupta A, Gupta B, Lal B. Effect of Tigonella foenum-graceum (fenugreek) seeds on the glycemic control and insulin resistance in type 2 diabetes mellitus:a double blind placebo controlled study. J Assoc Physicians India. 2001;49;1057-61.

17. Vijayakumar MV, Singh S, Chhipa RR, Bhat MK. The hypoglycaemic activity of fenugreek seed extract is mediated through the stimulation of an insulin signalling pathway. British Journal of Pharmacology. 2005;146(1):41-8.

18. Ramesh Babu K, Yogesh, Raghvendra HL, Kantikar SM, Prakash KB. Antidiabetic and histopathological analysis of fenugreek extract and alloxan induced diabetic rats. Int J Drug Dev\& Res. 2010;2(2):35664.

19. Muraki E, Hayashi Y, Chiba H, Tsunoda N, Kasono K. Dose-dependent effects, safety and tolerability of fenugreek in diet-induced metabolic disorders in rats. Lipids Health Dis. 2011;10:240.

20. Puri D, Prabhu KM, Murthy PS. Mechanism of action of a hypoglycemic principle isolated from fenugreek seeds. Indian J Physiol Pharmacol. 2002;46(4):457-62.

21. Haeri MR, Limaki HK, White CJ, White KN. Noninsulin dependent anti-diabetic activity of $(2 \mathrm{~S}, 3 \mathrm{R}$, 4S) 4-hydroxyisoleucine of fenugreek (Trigonella foenum graecum) in streptozotocin-induced type I diabetic rats. Phytomedicine. 2012;15;19(7):571-4.

22. Sauvaire Y, Petit P, Broca C, Manteghetti M, Baissac Y, Fernandez-Alvarez Jl. Hydroxyleucine, a novel potentiator of insulin secretion. Diabetes. 1998;47(2):206-10.

23. Ribes G, Sauvaire Y, Da Costa C, Baccou JC, Loubatieres-Mariani MM. Antidiabetic effects of subfractions from fenugreek seeds in diabetic dogs. Proc Soc Exp Biol Med. 1986;182(2):159-66.

Cite this article as: Kaur M, Singh N, Sharma G, Singh D. To study the efficacy and tolerability of fenugreek seed powder as add-on therapy with metformin in patients of type-2 diabetes mellitus. Int $\mathbf{J}$ Basic Clin Pharmacol 2016;5:378-83. 